\title{
Development Strategy of Infrastructure Risk Assessment Based Disaster Response and Management System
}

\author{
Eun-Ho Oh'1, Kyoon-Tai Kim¹, Kyong-Hoon Kim¹, Jin-Man Kim², Jin-Woo Cho' \\ ${ }^{1}$ Construction Management \& Economy Research Division, Korea Institute of Construction Technology, \\ Goyang-Si, Gyonggi-Do, South Korea \\ ${ }^{2}$ Geotechnical Engineering Research Division, Korea Institute of Construction Technology, Goyang-Si, \\ Gyonggi-Do, South Korea \\ Email: uno1988@kict.re.kr, jmkim@kict.re.kr
}

Received May 2014

\begin{abstract}
Major infrastructures such as levee, dam, bridge, road, etc. have a significant meaning in that they are the means to support ordinary social and industrial activities and also protect human and physical assets at the occurrence of disaster. Especially, integrated risk management of SOC facilities provides the policy maker in charge of SOC facility safety and related disaster prevention with a reasonable means of decision making and ultimately contributes to improving the safety of the applicable SOC facility. Furthermore, a variety of issues raised in the Sewol ferry disaster that occurred recently in Korea, such as, a proper response method and the relevant Golden time decision making at the occurrence of disaster, rapid grasping and reporting the situation on disaster sites, management and mobilization of resources for rescue and recover, loss of integrated control tower function, etc., might occur as well in facility disaster management. As the method of solving such issues adequately, this study suggests a strategy of new disaster response and management system. The analyses of Hazus-MH (FEMA) and DIMSuS (Purdue University) were comprehensively conducted, and based on the results required functions of new disaster response system of major infrastructure and its development directions were suggested.
\end{abstract}

\section{Keywords}

Infrastructure, Risk Assessment, Disaster, Response, Decision-Making

\section{Introduction}

Major facilities such as levee, dam, bridge, road, etc. have a significant meaning in that they are the means to support ordinary social and industrial activities and also protect human and physical assets at the occurrence of disaster. Especially, integrated risk management of SOC facilities provides the policy maker in charge of SOC facility safety and related disaster prevention with a reasonable means of decision making and ultimately con- 
tributes to improving the safety of the applicable SOC facility. Furthermore, a variety of issues raised in the Sewol ferry disaster that occurred recently in Korea, such as, a proper response method and the relevant Golden time decision making at the occurrence of disaster, rapid grasping and reporting the situation on disaster sites, management and mobilization of resources for rescue and recover, loss of integrated control tower function, etc., might be occurred as well in facility disaster management. As the method of solving such issues adequately, this study suggests a strategy of new disaster response and management system.

\section{Establishment of Risk Assessment Concept}

It is necessary to establish a concept of risk assessment in advance in order to build DRiMSS (Disaster Risk

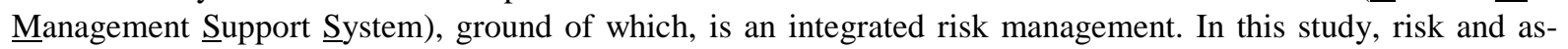
sessment concept of DIMSuS developed by Purdue University and Hazus-MH developed by FEMA were analyzed, and then a new concept of risk assessment was established.

\subsection{Concept of Risk Assessment in Hazus-MH}

Risk assessment of Hazus-MH was developed aiming for guiding each local government in establishing its plan for risk analysis and disaster mitigation under the Disaster Mitigation Act (Disaster Mitigation Act of 2000). Disaster mitigation plan required under the Disaster Mitigation Act, however, is designed to handle the development of disaster management policy and enforcement guidelines, risk analysis and mitigation techniques, and loss forecasting technique, etc. in general, while the risk assessment of Hazus-MH is based on loss forecast designed to assess the level of risk following the scale of damage to major facilities, local community and industry except facility or disaster risk management in consideration of probability.

\subsection{Concept of Risk Assessment in DIMSuS}

Risk handled in DIMSuS represents the degree of risk (Risk, Threats) affected to society and industry by disasters. Its value depends on the condition of major facilities, and the risk is calculated by the probabilistic method. Broadly, the risk of facility is decided according to the probability of damage that may occur and the size of damage related with functional destruction and structural destruction. Probabilities of functional and structural damages are derived based on the damage arising from the occurrence of flood, that is, Bayesian Network using the conditional probability, and the mechanism of functional and structural damages is realized and final risk that may impact on society and industry is calculated using the System Dynamics Simulation technique.

Hazus-MH simply provides risk manager with information such as flooded area, scale of damage, etc. while DIMSuS plays a role of supporting decision making so that risk manager can properly judge related with management of damaged region and response to the region. Especially, it suggests the procedure of assessment through DIMSuS-3D (3-Dimension) so that DIMSuS can conduct crisis management at the occurrence of disaster, and indicate the basic points of EAP (Emergency Action Plan) by facility types.

\subsection{Establishment of the Concept of Risk Assessment in DRiMSS}

In establishing the concept of risk assessment pursued by DRiMSS in this study, it is desirable to introduce and apply the concept of DIMSuS aimed at decision making of the risk manager rather than Hazus-MH that simply provides information. Therefore, overall information such as EAP for major facilities in force-land and the facilities in frequently flooded area of protected lowland should be provided on the assumption that safety information and failure probability related with the facility are provided on a real time basis to DRiMSS.

DIMSuS, however, falls short of grasping the scale of damage in the applicable region and related decision making, and therefore the suggestion of comprehensive EAP using the information of damage analysis in the DRiMSS should be included. Final product of DRiMSS risk assessment consists of level of risk by major facilities, result of risk analysis for the applicable region, and information in detail of EAP of the major facilities and the applicable region.

\section{Facility Impact Flow Analysis for Risk Assessment}

DRiMSS risk assessment is conducted related with a primary risk affected to the water front structure at the occurrence of disaster and the secondary or direct/indirect risk of the society and industry in the vicinity that may 
occur from the destruction of water front structure. Therefore, it is important to grasp physical vulnerability of water front structure to which the external force is directly applied when the disaster such as flood, etc. occurs in the beginning and the probability that such vulnerability may occur. In addition, it is necessary to grasp the risk that may occur in succession in the ambient structure, residential area or industrial area being transferred secondarily thereafter. Accordingly this study intended to analyze the flow of impact as well as disaster risk mechanism required for risk assessment.

According to Oh (2008), natural disaster impact applied to the facility or related society/industry through basic cell model is divided into Primary and Secondary steps. Primary step means physical impact from natural disaster being directly applied to the facility, which is a step causing physical damage or loss. For example, typhoon is accompanied by the destructive force such as wind, rain, flood, tidal wave, etc., which comes to cause direct damages such as flooding, destruction, collapse in part, etc. to the facilities (Figure 1) [1].

Secondary step is the stage causing secondary damages such as flood, outage of electricity, break in communications, bridge collapse, road flooding, etc. to the facilities or industry in one or two-way connection with the facilities that underwent damage. Such disaster impact or damage route was illustrated in Figure 2.

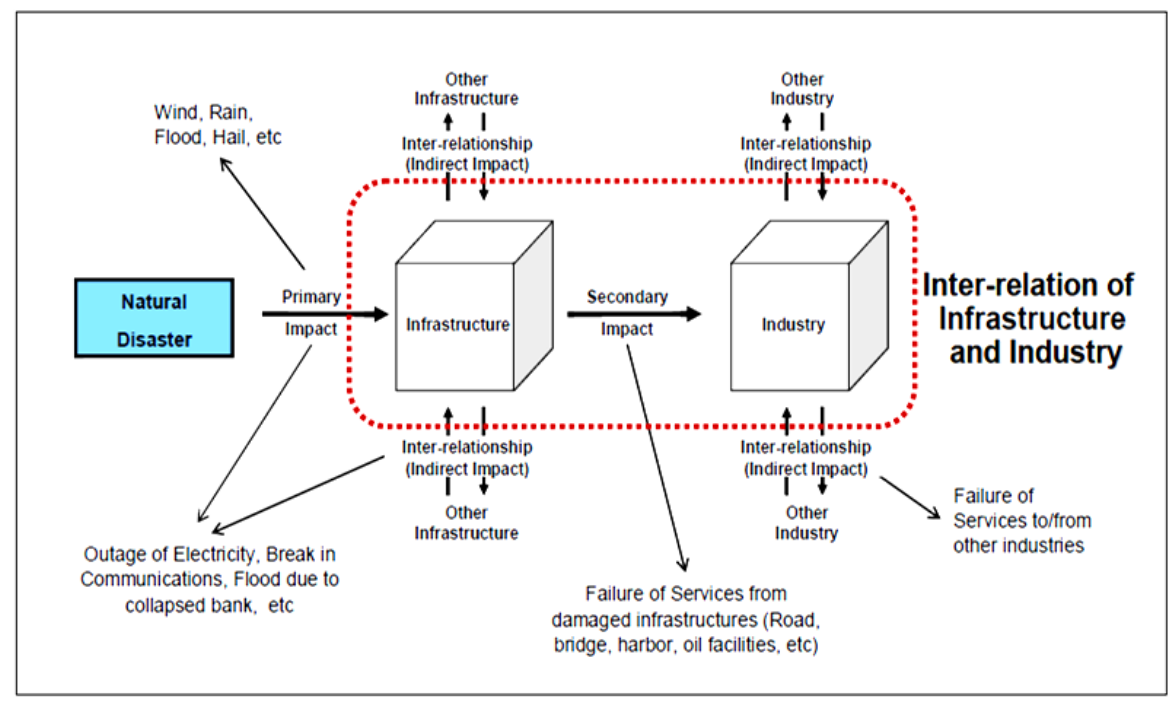

Figure 1. Disaster impact mechanism: Basic cell model (Oh, 2008).

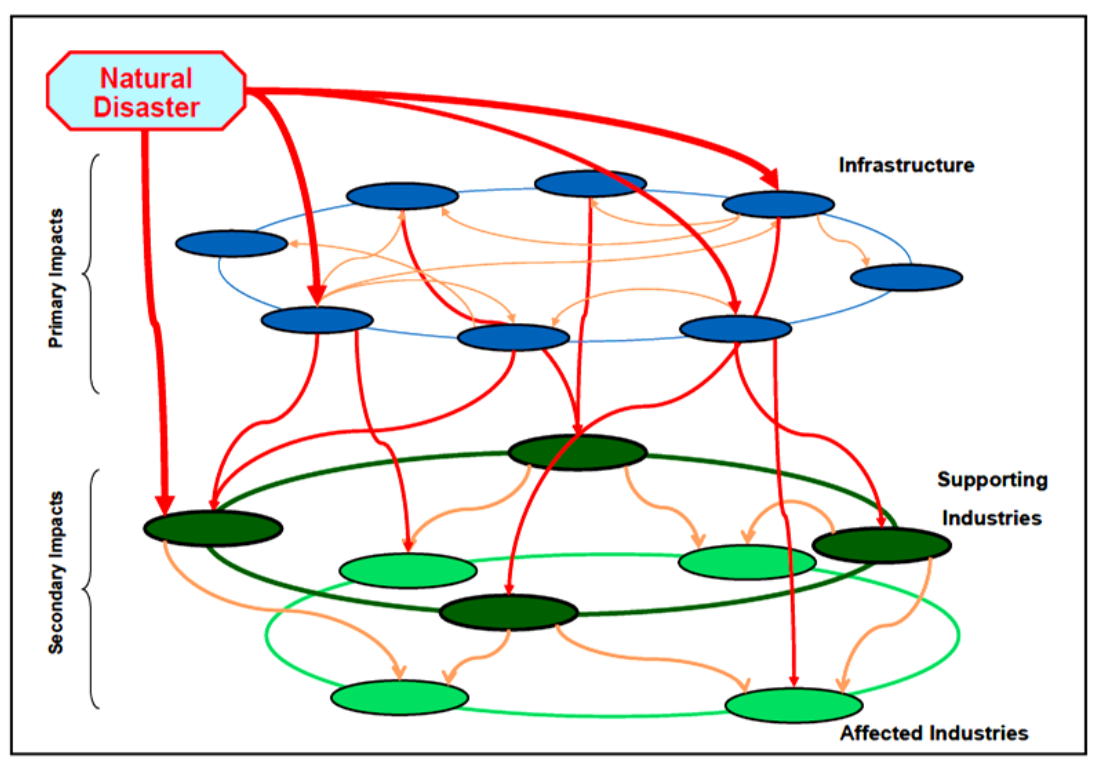

Figure 2. Conceptual disaster impact diffusion route (Oh, 2008). 
Pattern of disaster impact diffusion depends on the regional characteristic of the area where disaster occurs. Therefore, it is necessary to decide a specific region as the test bed in order to develop DRiMSS that is the final aim of research in this study, analyze the characteristic of society and industry in the applicable region, and analyze the degree of mutual supporting and dependency relationship between the major facilities that support the same. In addition, it is essential to exactly grasp inter-relationship between the facilities based on flood scenario to analyze the flow of impact that is deployed at the occurrence of flood. Inter-relationship between the facilities explains which facility is primarily exposed to risk or impact at the occurrence of flood geographically, which facility or socio-industrial entity undergoes sequential impact directly or indirectly when the facility is flooded resulting in functional/structural destruction, etc.

\section{Analysis of Decision Making Supporting System Related with Risk \\ 4.1. Analysis of Hazus-MH Risk Assessment Elements and Method}

In America, there are the statutes related with disaster and disaster management such as Robert T. Stafford Disaster Assistance and Emergency Relief Act, Disaster Mitigation Act (2000), Homeland Security Act (2002), HSPD-5, etc. They establish a disaster management system in accordance with "Comprehensive Disaster and Safety Management Technology Development Plan (2007)” of SDR (Subcommittee on Disaster Reduction) under control of NSTC related with 6 policy directions to mitigate disaster risk in future.

6 policy directions aimed in this comprehensive plan are "1) Use of natural and human disaster technologies to prevent terror, 2) Establishment of disaster information and reinforcement of forecasting competence, 3) Development of risk assessment model and its linkage to decision making supporting system, 4) Rapid application of hazard study, 5) Increase in mitigating technology activity and its incentives, 6) Reinforcement of risk communication competence and public alert system technique."

Based on such legal ground and recommendation, USA operates disaster management system including the homeland security concept such as terror, etc. in the response to disaster, and uses the technological alternative such as disaster management purpose communication system (AMSC SkyCell system, mobile satellite communication system) and GIS-based disaster management system (Hazus-MH) against natural disaster such as earthquake, hurricane, flood, etc. This paragraph analyzes Hazus-MH disaster damage based risk assessment procedure.

In case of flood model, Hazus-MH visualizes flooded area and is very effective in calculating the scale of direct and indirect economic damages and damage for humans (social damage) based on inventory information. FEMA suggests the procedure of risk assessment (How-To Guide) based on this Hazus-MH in detail (FEMA, 2004) [2]. This assessment procedure is designed to guide the establishment of risk analysis and disaster mitigation plan that had to be conducted by each local government under the Disaster Mitigation Act enforced from 2000, which was developed as the demonstration application guideline of Hazus-MH. Disaster mitigation plan required by the Disaster Mitigation Act includes development of disaster management policy/enforcement guideline, risk analysis/mitigation technique, loss forecasting technique, etc. As the tool to cope with the same, FEMA suggested 4-step risk assessment procedure based on Hazus-MH, which consists of Organize resources, Assess risks, Develop a mitigation plan, and Implement the plan and monitor. Basic 5 steps of risk assessment include Identify hazards, Profile hazards, Inventory assets, Estimate losses as well as and Hazus-MH simulation, and Consider mitigation option (Figure 3).

Nevertheless Hazus-MH is a tool aimed at damage estimation, but not a risk management tool for facility or related entity by probability. 5-step risk assessment procedure as aforementioned calculates in advance flood level and facility flooding damage of the applicable region using rainfall information given before the occurrence of flood or hurricane playing a role of providing prior information to mitigate direct/indirect damage, but Hazus-MH itself doesn't directly provide the risk information following the elapse of time. For example, it is impossible to provide regional risk information changing from moment to moment at the occurrence of flood, vulnerability by facilities, information on the response by stages, etc. in Hazus-MH.

\subsection{DIMSuS Unit and Whole Risk Assessment Algorithm}

Unit algorithm of DIMSuS expressed the System Dynamics is divided into the flows of calculating two parts such as functional and structural risks. Bayes' theory is its central logic to calculate the sizes of occurrence 


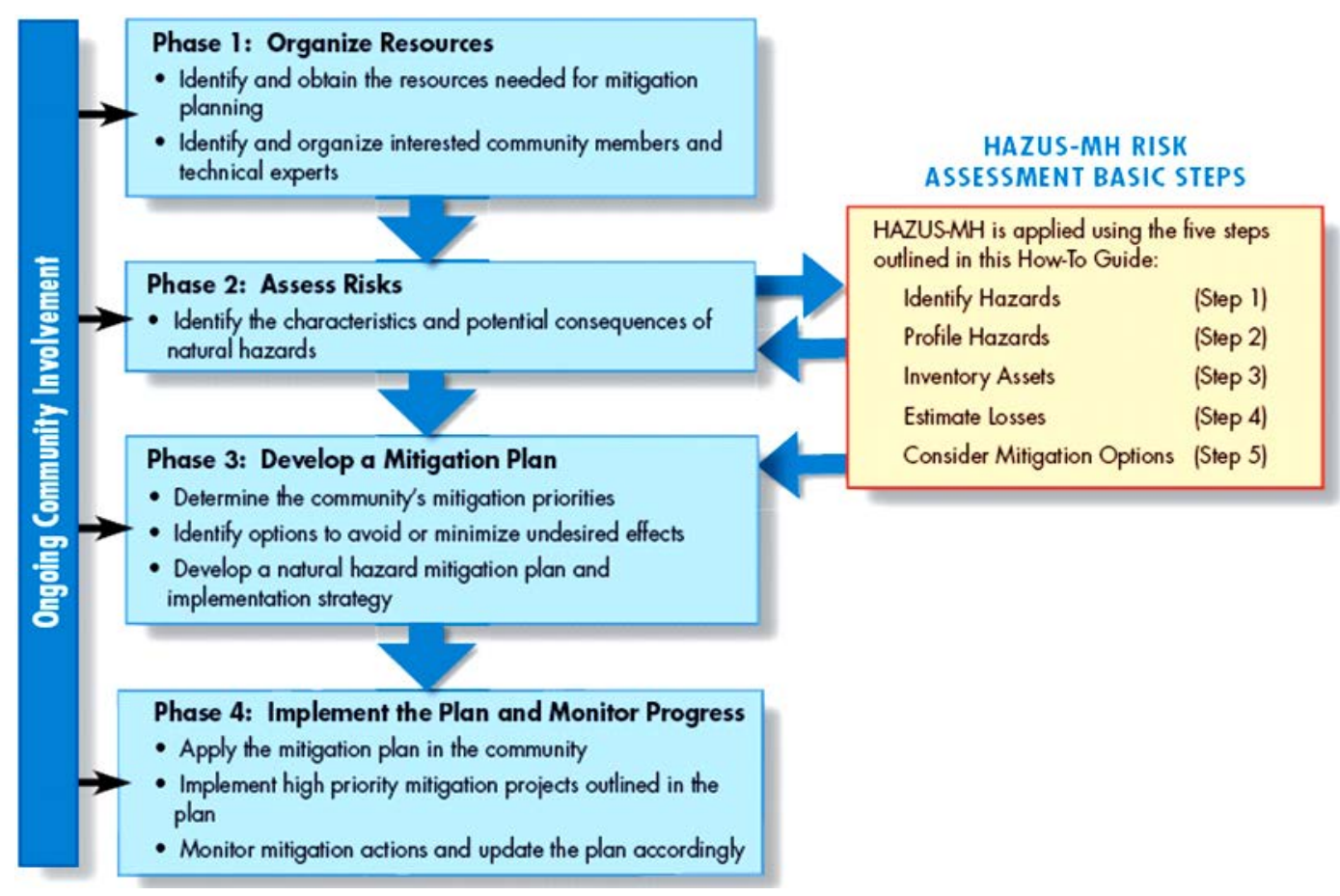

Figure 3. FEMA’s Hazus-MH based risk assessment procedure (FEMA, 2004).

probability and vulnerability, which is based on the conditional probability that preceding event gives conditional impact to lagging event [3].

This is because it is adequate for the calculation of risks of neighboring community, industry, and public facility where damages take place sequentially in connection of geography and time from the risk of destruction that starts from levee at the occurrence of flood disaster.

Figure 4 shows how the two preceding events such as Flood Level (FL) and State of Good Repair (SOGR) affect impact functionally or structurally to the levee. In case of functional risk, it reaches to 100 percent when the levee simply overflows, that is, flood level is higher than the height of levee, and therefore it is nothing to do with the condition of levee. Meanwhile, in case of structural risk, the pattern of destruction varies depending on the condition of levee; sound (SOGR1) or very vulnerable (SOGR4), and therefore it requires both flood level and status information as the preceding events.

Figure 5 shows the flow of the least unit impact that cause structural/functional risk (vulnerability) to the levee by the factors that generates the risks such as flood level (FL), facility condition (SOGR), pressure (Water pressure), etc.

Unit algorithm of DIMSuS can be diffused to the unit of major facilities such as bridge, road, plant, etc. starting form levee. Figure 6 as below shows the figure expanded into the whole risk assessment algorithm regarding the Diamond V a chain company in the region using the unit algorithm [3].

The result of DIMSuS risk assessment is derived in the form of graph provided by the System Dynamics, and expressed in the size of risk on $\mathrm{Y}$-axis and the elapse of time on $\mathrm{X}$-axis (Figure 7).

For example, total sum of functional risk (FD-LSA: Functional Damage of Levee Section A) and structural risk (SD-LSA: Structural Damage of Levee Section A) comes to the risk of Levee (Levee section A) that is the unit facility. Comprehensive risk of industry (Diamond V) is the total sum of the individual risks transferred through inter-relationship from power plant, transportation facility, levee, pump (waterworks), etc. In this case, the weighted value by facilities applied to get the sum of risks are those decided in advance by expert's opinion and inter-relationship between facilities (Level of Criticality).

As such, DIMSuS expresses the risks transferred from flood disaster in a graph by assessing them in functional/structural manner, and create/provide the relative risks suitable for manager or policy maker, but fails to provide exact damage information based on GIS and inventory information like Hazus-MH. Furthermore, it requires information on SOGR as the first input data and destruction probability of the levee based on it, which, 


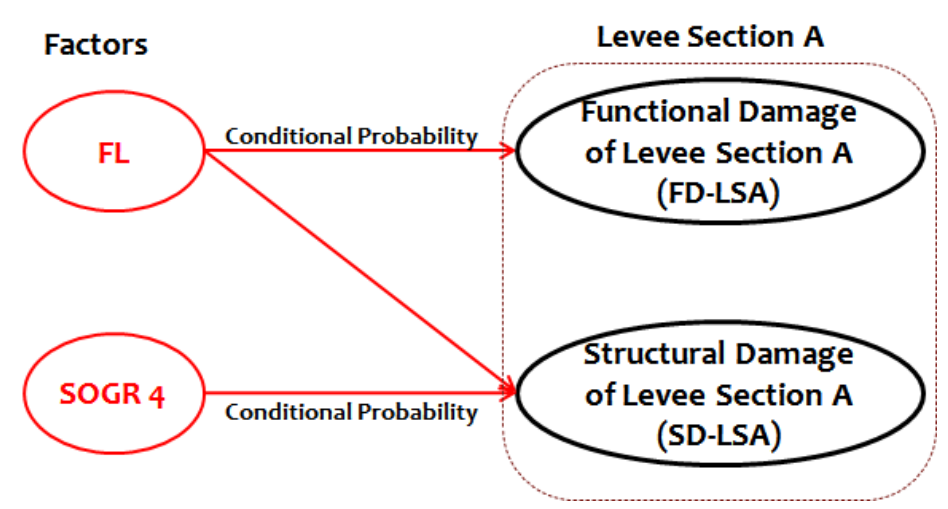

Figure 4. Conditional probability based functional/structural risk flows (Oh, 2010).

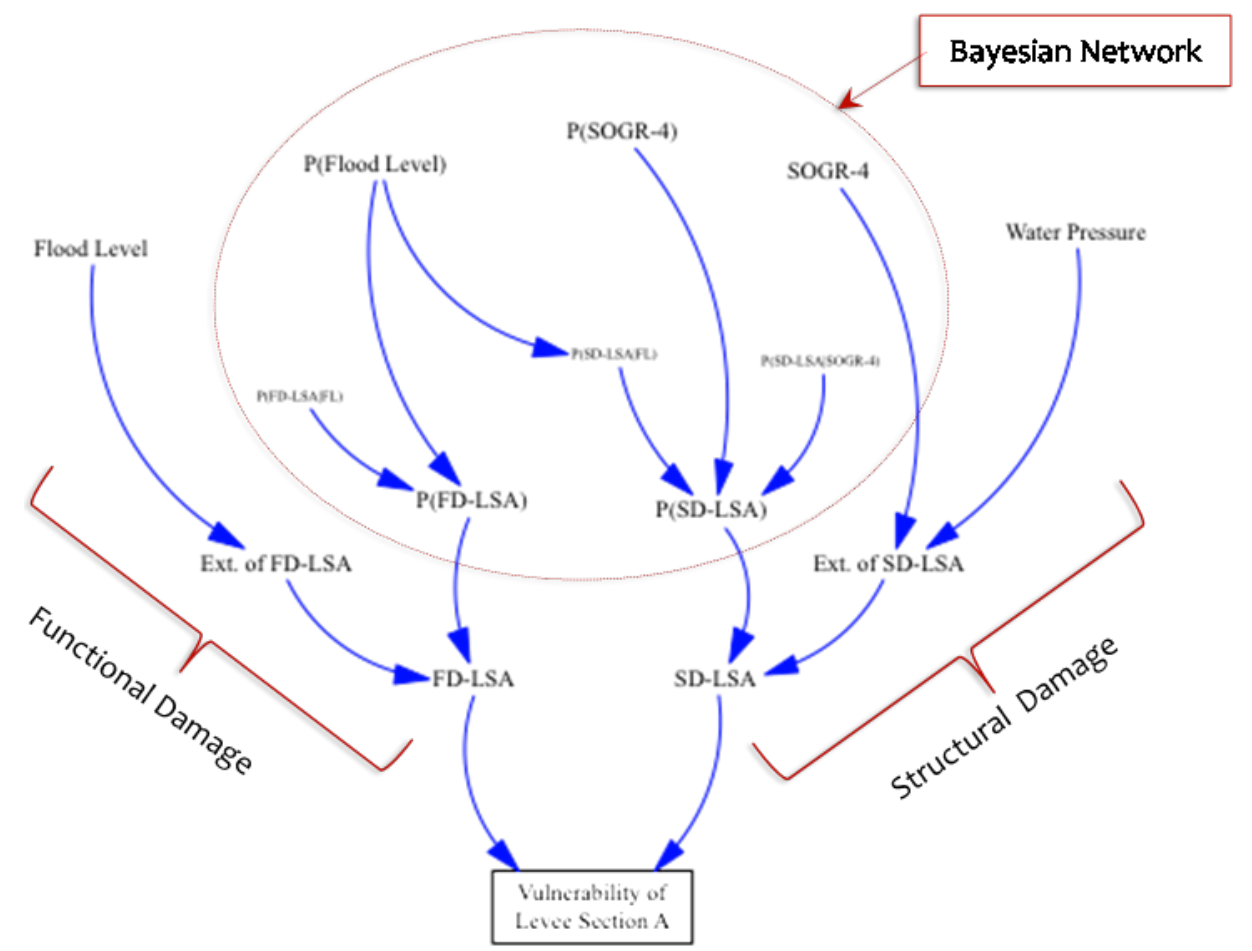

Figure 5. Unit algorithm of DIMSuS model (Oh, 2010).

however, is a theoretical assumptive value only. In fact, destruction probability of the levee is decided by piping and activity that occurs inside the levee and the overflow that occurs outside, which arises from complex reaction of a variety of conditions such as flood level, flooding time, material property of levee, design method and scale, size or length of collapsed area as well as the information of condition of the levee. That is, even Netherland and Japan, etc. advanced in the levee cannot officially provide destruction probability based on such factors of destruction so far. Accordingly, in order to supplement disaster decision making system based on DIMSuS facility risk, it is necessary to derive the levee destruction mechanism, and apply levee destruction probability based on overflow, activity, piping, etc.

\section{Development Direction for Facility Risk Assessment Based Disaster Risk Management Supporting System}

Hazus-MH enables exactly to the scope of actual flood area and damage to manor facilities based on precise inventory/DEM/flooding model information. It also calculates damage information covering direct/indirect damage 


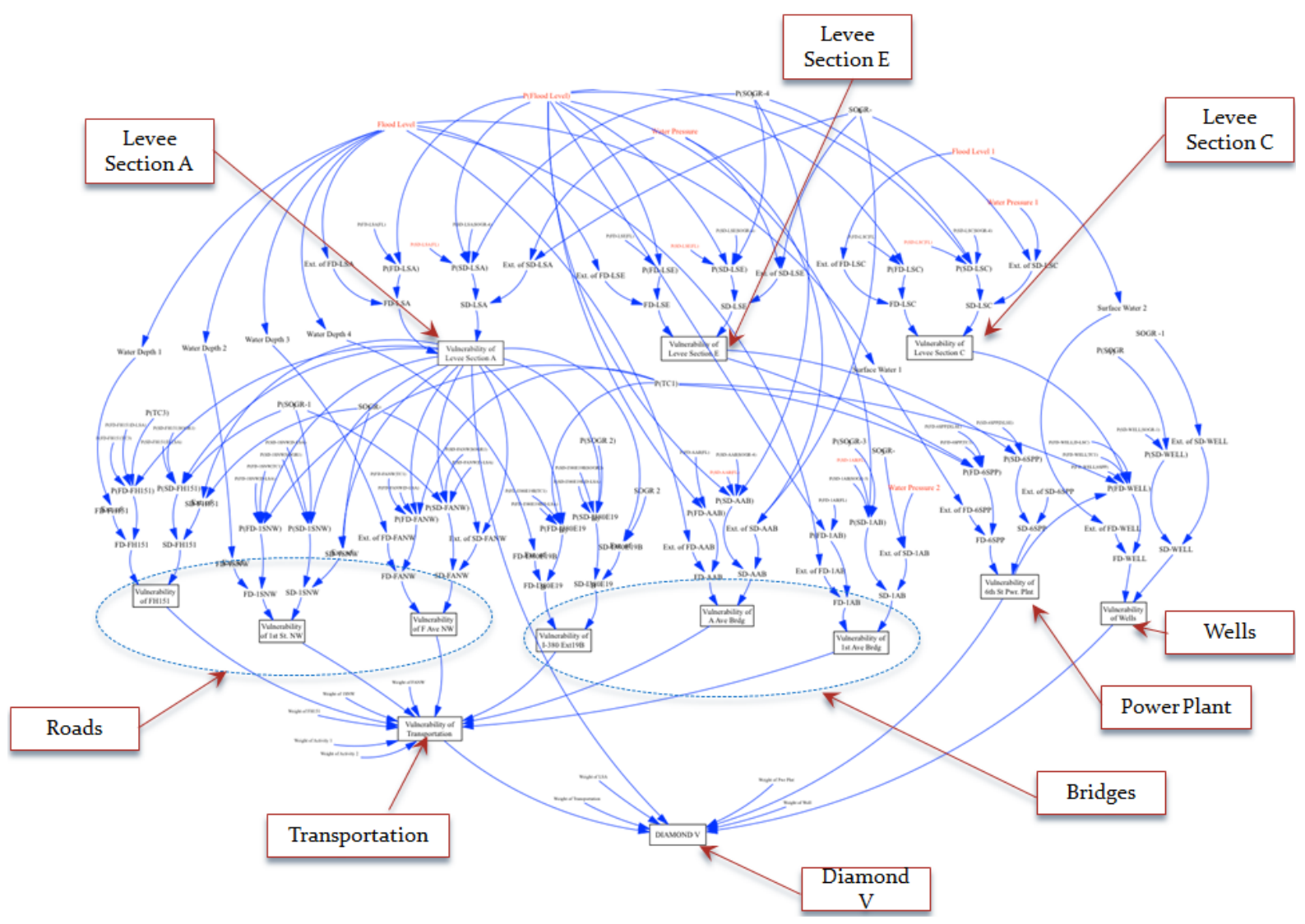

Figure 6. Industry risk assessment algorithm of DIMSuS model (Oh, 2010).

- Level of Vulnerability of Diamond V and its timeline

- Levee Section A

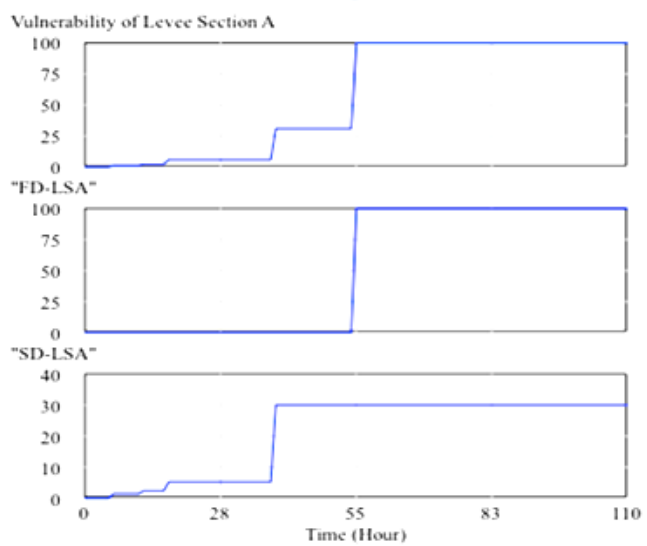

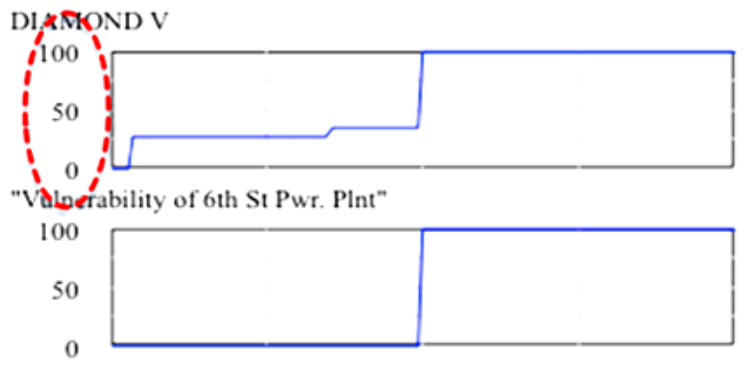

Vulnerability of Levee Section A

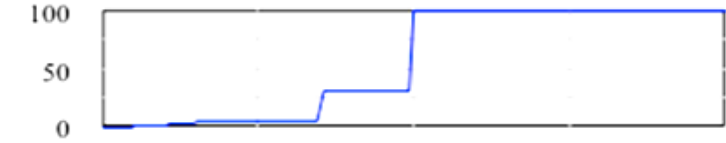

Vulnerability of Transportation

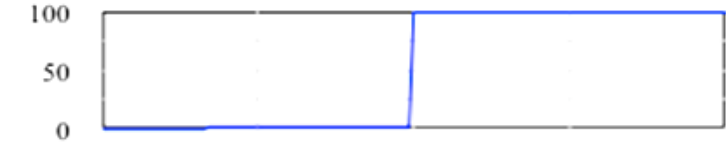

Vulnerability of Wells

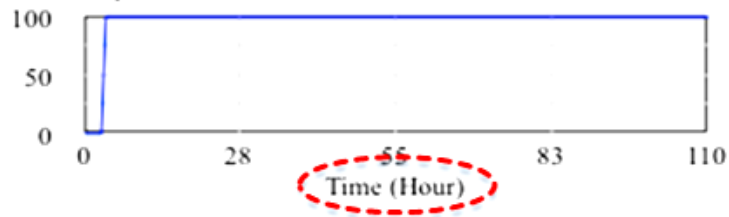

Figure 7. Indication of result of DIMSuS industry risk analysis (Oh, 2010). 
such as facility, community and industry, etc., and secures scientific and objective data. However, it is difficult for the manager to operate it as it adopts ArcGIS geographical information across U.S.A and inventory.

Meanwhile, DIMSuS considers conditional probability owing to flood and the inter-relationship of the applicable area and the degree of criticality and risk by facilities (SD, FD), and therefore enables to grasp the risk applied to the facility in accordance with the scenario (time, flood level, etc.). In addition, the input data includes the socio-industrial criticality of the applicable area facility and therefore it may provide priority level of the restoration stage afterwards as well as risk assessment. However, input data in part includes the opinion of experts or residents in the applicable region, and the level of risk calculated is expressed in a relative value, which is helpful in decision making but inadequate for the calculation of exact level of risk and scale of damage.

As result of analyzing the method of risk assessment related with the afore-mentioned two systems, it is deemed desirable that DRiMSS should apply the same simulation technique adopted in DIMSuS for the following reasons, and it is necessary to build a DRiMSS risk assessment model by applying the System Dynamics simulation tool that may satisfy the following condition.

- Water disaster management system targeted by DRiMSS is same as that by DIMSuS

- DRiMSS includes complex and a number of factors (facility)

- Inter-relationship between the constitutional factors of DRiMSS can be expressed in conditional probability of Bayesian Network based on the water disaster

- Inter-relationship of DRiMSS is expressed in a fixed formula

- Result of DRiMSS simulation is expressed in a continued data such as flood curve, risk, etc.

- Construction of DRiMSS simulation system is realized at the macro level as shown in DIMSuS

In addition, as result of bench-marking of the advantages of Hazus-MH and DIMSuS as shown in Table 1, DRiMSS is required to exert the specification and performance as follow.

Table 1. Comparison of Hazus-MH and DIMSuS.

\begin{tabular}{|c|c|c|}
\hline & HAZUS-MH & DIMSuS \\
\hline Technique & $\begin{array}{ll}\text { - } & \text { ArcGIS } \\
\text { - } & \text { Inventory system } \\
\text { - } & \text { Flood and damage calculation model }\end{array}$ & $\begin{array}{ll}\text { - } & \text { Impact Flow Analysis } \\
\text { - } & \text { System Dynamics technique } \\
\text { - } & \text { Bayes' Theory }\end{array}$ \\
\hline Input information & $\begin{array}{ll}\text { - } & \text { Inventory (National Inventory) } \\
\text { - } & \text { Flood Information(USGS) } \\
\text { - } & \text { DEM information }\end{array}$ & $\begin{array}{l}\text { - } \quad \text { Flood Scenario } \\
\text { AHP Result (information on the degree of criticality, } \\
\text { etc.) }\end{array}$ \\
\hline $\begin{array}{l}\text { Calculation } \\
\text { information }\end{array}$ & $\begin{array}{ll}\text { - } & \text { Scale of direct/indirect loss (absolute value) } \\
\text { - } & \text { Calculation of the scale of social damage }\end{array}$ & $\begin{array}{ll}\text { - } & \text { Degree of criticality of the facility } \\
\text { - } & \text { Facility risk (SD, FD) } \\
& \text { during disaster } \\
\text { - } & \text { FD (Functional Damage): Facility functional risk } \\
\text { during disaster }\end{array}$ \\
\hline $\begin{array}{l}\text { Disaster } \\
\text { management } 4 \\
\text { steps } \\
\text { Applicable scope }\end{array}$ & $\begin{array}{ll}\text { - } & \text { Long-term response } \\
\text { - } & \text { Response just before } \\
\text { - } & \text { Follow-up response }\end{array}$ & $\begin{array}{ll}\text { - } & \text { Long-term response } \\
\text { - } & \text { Response just before } \\
\text { - } & \text { Response at the occurrence (evacuation, rescue, etc.) }\end{array}$ \\
\hline $\begin{array}{l}\text { Manager } \\
\text { (View point) }\end{array}$ & - $\quad$ Government & $\begin{array}{ll}\text { - } & \text { Government } \\
\text { - } & \text { Industry } \\
\text { - } & \text { Local resident }\end{array}$ \\
\hline Advantages & $\begin{array}{ll}\text { - } & \text { GIS-based macro expression system } \\
\text { - } & \text { Exact forecast value } \\
\text { - } & \text { Scientific and quantitative calculation method }\end{array}$ & 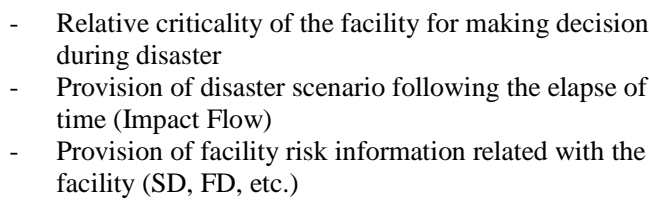 \\
\hline Disadvantages & $\begin{array}{l}\text { - Lack of concrete mitigation plan for } \\
\text { community and industry } \\
\text { - } \quad \text { Requirement of heavy GIS software }\end{array}$ & $\begin{array}{ll}\text { - } & \text { Lack of visible expression system } \\
\text { - } & \text { Relative value instead of absolute value } \\
\text { - } & \text { Focused on the expert's opinion }\end{array}$ \\
\hline
\end{tabular}


$<$ From DIMSuS $>$

- Conditional probability calculation method based on inter-relationship of the facility

- Function of simulation that enables to reproduce the system and provide the information repeatedly

- Active decision making system that may response just before and during the disaster

- Provision of risk information by facilities

- Assessment of the criticality of facility for long-term response and follow-up restoration related with disaster (provision of priority level)

$<$ From Hazus-MH>

- Use of geographical information based on detailed and accurate GIS

- Establishment of detailed inventory on the facility in the protected lowland and force-land (Total inspection)

- Calculation of detailed and accurate direct/indirect damage based on the Damage Curve by facilities

- 2D expression based on GIS

In addition, it is necessary to build DRiMSS as the decision making system improved in consideration of additional performances of the system that cannot be provided by Hazus-MH and DIMSuS as follow.

- The function of comprehensive assessment of the real-time based information by sensor delivered from the monitoring system

- Realization of levee destruction probability mechanism (in consideration of overflow, activity, piping, etc.)

- Supporting the facility manager to make proper decision (it must be the making of actually various decisions and the enforcement method thereby rather than the provision of simple information)

- GIS-based 3D expression and SNS information diffusion system

\section{Conclusion}

Facility risk assessment based DRiMSS suggested in this study is a first step for building advanced country type facility safety management and disaster response systems through integrated operation and linked technology, which would provide the basis for the existing manual disaster management system driven to human/physical damage mitigation to be converted into active response system that actively uses the facility. Currently DRiMSS has already been built in its conceptual design and establishment. For 4 years from now, its actual system establishment and demonstration experiment in the test bed region will be promoted.

\section{Acknowledgements}

This research was supported by a grant (13SCIPS01) from Smart Civil Infrastructure Research Program funded by Ministry of Land, Infrastructure and Transport (MOLIT) of Korea government and Korea Agency for Infrastructure Technology Advancement (KAIA).

\section{References}

[1] Oh, E.H. (2008) Identification of the Impact of Critical Infrastructure on Associated Industries: Analysis of a Flood Disaster Event. Master's Thesis, Purdue University, Indiana, USA.

[2] FEMA (2004) Using HAZUS-MH for Risk Assessment-How to Guide. FEMA 433, August.

[3] Oh, E.H. (2010) Impact Analysis of Natural Disaster on Critical Infrastructure, Associated Industries, and Communities. Ph.D. Dissertation, Department of Civil Engineering, Purdue University, Indiana, USA. 